\title{
Selective and sensitive lead (II) solid-contact potentiometric sensor based on naphthalene-sulfonamide derivative
}

\author{
A. Kamal · R. Tejpal • V. Bhalla - M. Kumar • \\ R. K. Mahajan
}

Received: 6 February 2014/Revised: 18 April 2014/ Accepted: 11 May 2014/Published online: 24 June 2014

(C) Islamic Azad University (IAU) 2014

\begin{abstract}
A new naphthalene-sulfonamide (NS) derivative has been used as ionophore to construct the polyvinylchloride-based lead (II) solid-contact (SC) coated graphite electrode modified with conducting polymer poly(3,4-ethylenedioxythiophene)/polystyrene sulfonate (PEDOT/PSS). The lead-NS derivative complex shows 1:1 stoichiometry with the maximum stability constant of 5.75 as compared to other metal ions that is determined by sandwich membrane method. The proposed membrane morphology has been analyzed by scanning electron microscopy. The proposed lead (II) SC-PEDOT/PSScoated graphite electrode-1 (Pb(II) SC-PEDOT/PSS-CGE1) shows the detection limit of $5.62 \times 10^{-8} \mathrm{M}(56.2 \mathrm{~nm})$ with Nernstian slope of $29.21 \mathrm{mV} /$ decade within the $\mathrm{pH}$ range of 2.0-7.0 and exhibits small response time of $<10 \mathrm{~s}$. It has been used as indicator electrode for the potentiometric titration of lead (II) with ethylenediaminetetraacetic acid and successfully applied for the determination of lead (II) ions content in various environmental and ayurvedic medicines sample matrices with very good performance (0.999 correlation coefficients in the comparison against atomic absorption spectroscopy method).
\end{abstract}

Electronic supplementary material The online version of this article (doi:10.1007/s13762-014-0621-0) contains supplementary material, which is available to authorized users.

A. Kamal · R. Tejpal · V. Bhalla · M. Kumar .

R. K. Mahajan $(\square)$

Department of Chemistry, UGC-Centre for Advanced Studies,

Guru Nanak Dev University, Amritsar 143005, India

e-mail: rakesh_chem@yahoo.co
Keywords Naphthalene-sulfonamide - Coated graphite electrode $\cdot$ Stability constant $\cdot$ Scanning electron microscopy $\cdot$ Environment

\section{Introduction}

Lead is a universal and versatile metal, which has been used by mankind for many years. It is the most serious environmental pollutant among the toxic heavy metals all over the world. The common sources of its exposure are use of certain products such as paints, cosmetics, environmental emission containing lead, lead acid batteries, Indian manufactured ayurvedic medicines (Saper et al. 2008; Gunturu et al. 2011). Lead has no biological benefit to human and wildlife. World Health Organization (WHO) has recommended a limit of $10 \mu \mathrm{gL}^{-1}$ $\left(4.80 \times 10^{-8} \mathrm{M}\right)$ of $\mathrm{Pb}(\mathrm{II})$ in potable water (Baird 1999). When lead starts accumulating gradually in human blood, they induce abdominal cramps, reproductive toxicity, learning disability, attention deflect disorder, and brain damage. Due to environmental and biological toxicity of lead, the detection of lead at low level especially in drinking water has forced particular attention of analytical chemists. Presently, the most common analytical methods used for the determination of lead in different samples are atomic absorption spectrophotometry (AAS) and inductively coupled plasma mass spectroscopy (ICPMS). Although both these techniques show good selectivity and low detection limit to lead ions, both of these methods are expensive and complicated to perform online and inline determination of lead in drinking water. Conversely, electrochemical techniques are cheap, portable, robust, and easy to handle. These techniques provide a crucial 
analytical tool for selective detection of various metal ions, drugs, and biomolecules (Sanghavi et al. 2013; Gupta et al. 2000, 2002, 2003, 2005, 2006a, b, c, d, 2007, 2011a, b, c, 2012, 2013; Mobin et al. 2010; Goyal et al. 2007, 2008a, b, c. 2009; Sanghavi et al. 2014).

The certain problems related to conventional polymeric ion-selective electrodes made with inner filling solutions such as drying out of the inner solution (need for maintenance), limitation of applications (electrode orientation, temperature, and pressure), unable to remote sensing, and deep sea measurements automatically disappear with solidcontact ion-selective electrodes (SC-ISEs) (Bobacka 2006; Chumbimuni-Torres et al. 2006; Lindner and Gyurcsanyi 2009). SC-ISEs make their applications in clinical diagnosis, industrial process control, in environmental monitoring and are the best alternative of the above-mentioned complicated method for the estimation of $\mathrm{Pb}$ (II) ions.

Many efforts have been made to construct $\mathrm{Pb}$ (II) ISEs by using different organic and inorganic compounds (Srivastava et al. 1995; Jain et al. 2006, Chen et al. 2006, Soleymanpour et al. 2012; Wardak 2011; Elmosallamy et al. 2008; Li et al. 2009; Michalska et al. 2009; Kazemi et al. 2009; Wilson et al. 2010; Abbaspour et al. 2010; Huang et al. 2011; Zamani et al. 2011; Yin et al. 2012; Lisak et al. 2012; Guzinski et al. 2013). Very recently, the Rong et al. (2012) reviewed the $\mathrm{Pb}(\mathrm{II})$ ISEs based on ionophores bearing oxygen/sulfur functional groups. They have also reported different applications of $\mathrm{Pb}$ (II) ISEs and drawbacks of methods used to calculate the selectivity coefficient. Recently, solid-contact $\mathrm{Pb}$ (II) ISEs prepared on screen-printed substrate was reported by Anastasova et al. (2012) with tremendous nanomolar detection of $\mathrm{Pb}$ (II) ions in local rivers water samples. Yuan et al. (2012) reported a schiff base complex that exploited as $\mathrm{Pb}$ (II) ISE with slope of $23.9 \mathrm{mV} /$ decade and detection limit of $4.6 \times 10^{-6} \mathrm{M}$.

It is well known that low detection limit can also be achieved using solid-contact ISEs based on conducting polymers (CP) as ion-to-electron transducers (Konopka et al. 2004; Michalska 2006) and also eliminate main drawback of solid-state ISEs with instable potential response which take place due to the formation of aqueous layer in between solid contact (metal, carbon) and the ionic conductor (ion-selective membrane). Recently, polyethylenedioxythiophene (PEDOT) and polyoctylthiophene (POT) have been used as the ion-to-electron transducer for the construction of various SC-ISEs (Bobacka et al. 2004; Vazquez et al. 2004; Paciorek et al. 2003; Sutter et al. 2004; Ochoa and Cordero 2010). In the present work, poly (3,4-ethylenedioxythiophene) (PEDOT) doped with poly (styrene sulfonate) (PSS), i.e., PEDOT/PSS as active ionto-electron transducer with plasticized PVC sensing membrane, has been used to avoid the aqueous layer at the interface of $\mathrm{Pb}$ (II) SC-ISEs.

In this paper, we present $\mathrm{Pb}(\mathrm{II}) \mathrm{SC}$-ISEs based on conducting polymer PEDOT/PSS as an ion-to-electron transducer and novel naphthalene-sulfonamide (NS) derivative acting as ionophore. The proposed $\mathrm{Pb}(\mathrm{II})$ SC-electrode based on NS derivative further applied in the analysis of $P b(I I)$ ions in various environmental and ayurvedic medicines sample matrices by direct potentiometry, and the results obtained were compared with atomic absorption spectroscopy (AAS) and volumetric methods.

\section{Materials and methods}

All reagents used were of analytical grade, and doubly distilled deionized water was used to prepare solutions. The ionophore naphthalene-sulfonamide (NS) derivative was synthesized as reported in the literature (Bhalla et al. 2012), and structure is shown in Figure (online resource 1). The plasticizers 2-nitrophenyl octyl ether (2-NPOE), bis(2-ethylhexyl) sebacate (DOS), bis(2-ethylhexyl) phthalate (DOP), bis(2-ethylhexyl) adipate (DOA), dibutylphthalate (DBP), tributylphosphate (TBP), and high molecular weight poly(vinyl chloride)(PVC) were used as received from Fluka. Anion excluder potassium tetrakis(4-chlorophenyl)borate (KTpClB) was obtained from Sigma-Aldrich, while lead (II) nitrate and other metal nitrates received from Merck were used without any further purification. Aqueous dispersion of poly(3,4-ethylenedioxythiophene) doped with poly(4-styrene sulfonate) anions (Baytron P) was obtained from Sigma-Aldrich and used as obtained.

Preparation of PEDOT/PSS modified solid-contact ionselective electrodes

Spectroscopic grade graphite rods $20.0 \mathrm{~mm}$ in length and $3.0 \mathrm{~mm}$ in diameter were used for the preparation of coated graphite electrodes. At one end of the graphite electrode, a shielded copper wire was glued and the electrodes were sealed into other end of a glass tube having the same diameter with epoxy resin (Araldite). The working surface of the electrodes was polished with fine alumina slurry on the polishing cloth, washed with double-distilled water, and then dried in air. About $100 \mu \mathrm{L}$ of aqueous suspension of PEDOT/PSS (Baytron P) was pipette and deposited on the bare surface of polished graphite rod (Bobacka 2006; Vazquez et al. 2004). On the other hand, membrane solution was prepared by thoroughly dissolving PVC, plasticizer, ionophore, and additive in $3.0 \mathrm{~mL}$ THF (composition given in Table 2). The resulting clear solution was evap- 
orated slowly at room temperature until an oily concentrate mixture was obtained. Then, dry PEDOT/PSS modified graphite electrode was coated with the prepared membrane solution and solvent allowed to evaporate at room temperature. A membrane was formed on the graphite surface, and electrode was allowed to stabilize overnight. The solidcontact polymer modified coated graphite electrodes (SCPEDOT/PSS-CGEs) was finally conditioned by soaking in $1.0 \times 10^{-2} \mathrm{M}$ lead nitrate solution for $72 \mathrm{~h}$ until it produced stable and reproducible potential. The potentiometric measurements were carried out using following electrochemical cell assembly:

\begin{tabular}{|c|c|c|c|c|}
\hline Graphite & PEDOT/PSS & PVC & Test & $3.0 \mathrm{M}$ \\
\hline Surface & Film & Membrane & Solution & $\mathrm{KCl}$ \\
\hline
\end{tabular}

All the measurements of electrode potential were made with an Equip-tronics model EQ-602 potentiometer. The $\mathrm{pH}$ and conductometric measurements were made using Elico LI model-120 pH meter and Equip-tronics model EQ-664A, respectively. The determinations of lead in different samples by using the reference method were made by employing atomic absorption spectrophotometer (AAS 4129, Electronic Corporation India Limited). For the scanning electron microscopy (SEM) study, the sample holders were cleaned and then dried with acetone solvent. The samples membranes were then fixed onto the holders and coated with gold in the vacuum chamber to increase the conductance of their surfaces. These samples were used to study the morphology of the membrane surfaces by using Carl Zeiss Supra ${ }^{\mathrm{TM}}$ 55, Germany model SEM.

\section{Results and discussion}

Preliminary complexation study of naphthalenesulfonamide (NS) derivative

In order to obtain a knowledge about the stability and stoichiometry of NS derivative with the number of alkali, alkaline earth, and transition metal ions, the NS derivative complexation studies were investigated conductometrically in acetonitrile solutions at $298 \mathrm{~K}$ (Singh and Singh 2010; Shamsipur and Ganjali 1997). The $25 \mathrm{~mL} 1.0 \times 10^{-4} \mathrm{M}$ metal ion solution was titrated with NS derivative of ( $L=$ liganad) $1.0 \times 10^{-3} \mathrm{M}$ and the conductance of the mixture, after each addition of titrate was measured. The Fig. 1 showed the conductance variation plots with various metal ions $\mathrm{CM}^{\mathrm{n}+}=\mathrm{Hg}^{2+}, \mathrm{Ni}^{2+}, \mathrm{Co}^{2+}, \mathrm{Cd}^{2+}, \mathrm{Fe}^{3+}, \mathrm{Ca}^{2+}$ and $\mathrm{Zn}^{2+}$ ) in addition to $\mathrm{Pb}$ (II) ions. The conductance decreases in the beginning on the addition of ionophore that shows that

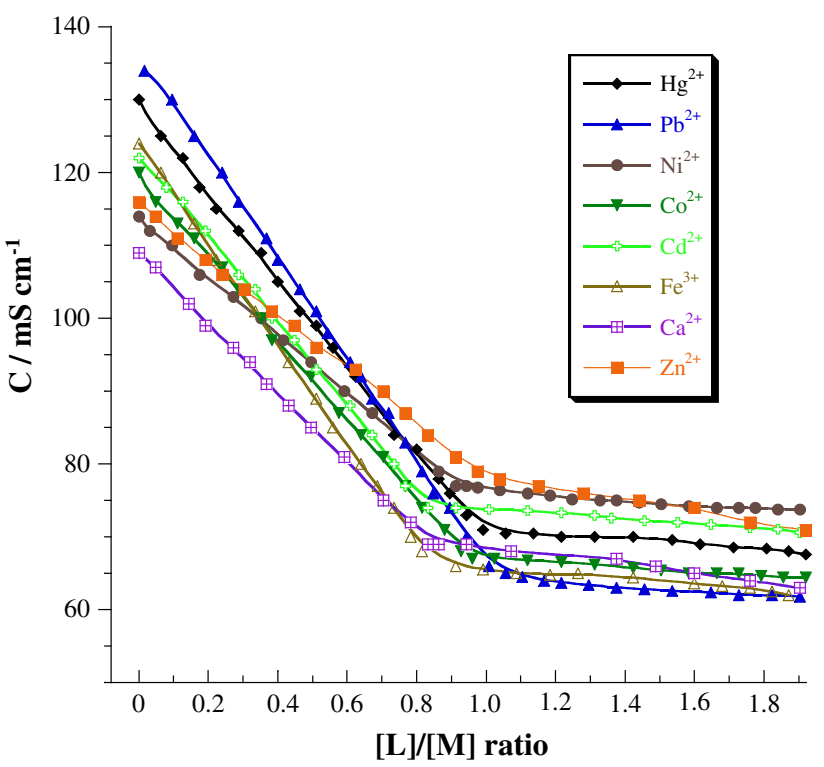

Fig. 1 Plot of conductivity versus ligand/metal ratio with different metal ions

the metal ions interaction with the ionophore forming a large complex, so decreasing in conductance. At a point, the addition of ionophore does not significantly decreases and conductance become nearly constant. Break in the plot represent the stoichiometry of complex and found to be 1:1.

\section{Determination of stability constants}

The formation constant of the ion-ionophore complex within the membrane phase is an important parameter that indicates the selectivity of the sensor. The ion-ionophore complex formation constants were evaluated by potentiometric method (Mi and Bakker 1999; Qin et al. 2000). In this method, a sandwich membrane is prepared by fusing two membranes, with only one containing the ionophore. This membrane electrode was brought in contact with the aqueous solution, having identical concentration on both sides, and cell potential was measured. On the other hand, the cell potential of another membrane having no ionophore was measured. The membrane potential $\left(E_{\mathrm{M}}\right)$ is determined by subtracting the cell potential of membrane without ionophore from the sandwich membrane. The formation constant is then calculated from the following equation:

$\beta_{\mathrm{IL}_{\mathrm{n}}}=\left(L_{\mathrm{T}}-\frac{n R_{\mathrm{T}}}{Z_{\mathrm{I}}}\right)^{-n} \exp \left(\frac{E_{\mathrm{M}} Z_{\mathrm{I}} F}{R T}\right)$

where $L_{\mathrm{T}}$ is the total concentration of ionophore in the membrane segment, $R_{\mathrm{T}}$ is the concentration of lipophilic ionic sites additive, $n$ is the ion-ionophore complex stoi- 
chiometry, and $R, T$, and $F$ are gas constants, the absolute temperature, and Faraday constant, respectively, $Z_{1}$ is the charge on ion.

Table 1 The formation constant of NS derivative- $\mathrm{M}^{\mathrm{n}+}$ complexes using sandwich method

\begin{tabular}{llll}
\hline Metal ions & $\begin{array}{l}\text { Formation constant } \\
\left(\log \beta_{\mathrm{IL}_{\mathrm{n}}} \pm \mathrm{SD}\right)^{a}\end{array}$ & Metal ions & $\begin{array}{l}\text { Formation constant } \\
\left(\log \beta_{\mathrm{IL}_{\mathrm{n}}} \pm \mathrm{SD}\right)^{a}\end{array}$ \\
\hline $\mathrm{Pb}^{2+}$ & $5.75 \pm 0.05$ & $\mathrm{Mg}^{2+}$ & $2.65 \pm 0.04$ \\
$\mathrm{Cd}^{2+}$ & $3.43 \pm 0.03$ & $\mathrm{Hg}^{2+}$ & $4.20 \pm 0.08$ \\
$\mathrm{Co}^{2+}$ & $3.89 \pm 0.05$ & $\mathrm{Li}^{+}$ & $2.43 \pm 0.07$ \\
$\mathrm{Cu}^{2+}$ & $4.01 \pm 0.08$ & $\mathrm{Ca}^{2+}$ & $3.30 \pm 0.04$ \\
$\mathrm{Zn}^{2+}$ & $3.22 \pm 0.02$ & $\mathrm{~K}^{+}$ & $3.05 \pm 0.03$ \\
$\mathrm{Fe}^{3+}$ & $2.89 \pm 0.01$ & $\mathrm{Na}^{+}$ & $2.95 \pm 0.05$ \\
$\mathrm{NH}_{4}^{+}$ & $1.76 \pm 0.06$ & $\mathrm{Ni}^{2+}$ & $3.68 \pm 0.02$ \\
\hline
\end{tabular}

${ }^{\text {a }}$ Mean value \pm standard deviation (three measurement)
The stability constants of different complexes calculated by the sandwich method are given in Table 1 in which the formation constant $\left(\log \beta_{\mathrm{IL}_{\mathrm{n}}}\right)$ for Pb(II)-NS complex is maximum (5.75), so ionophore shows maximum affinity toward $\mathrm{Pb}$ (II) ions. On the other hand, the stability constants for other metal ions are less than $\mathrm{Pb}$ (II) ions, which indicate the less affinity of ionophore toward these metal ions. Because of this affinity difference, it is expected that the presented NS derivative ionophore will facilitate the transport of $\mathrm{Pb}$ (II) ions in preference to other metal ions. Therefore, the NS derivative ionophore can be used as potential ionophore for preparing solid-contact $\mathrm{Pb}$ (II) ionselective electrode.

\section{Surface characterization}

One of the important aspects of ion-selective electrode is the microstructure of the membrane material, which
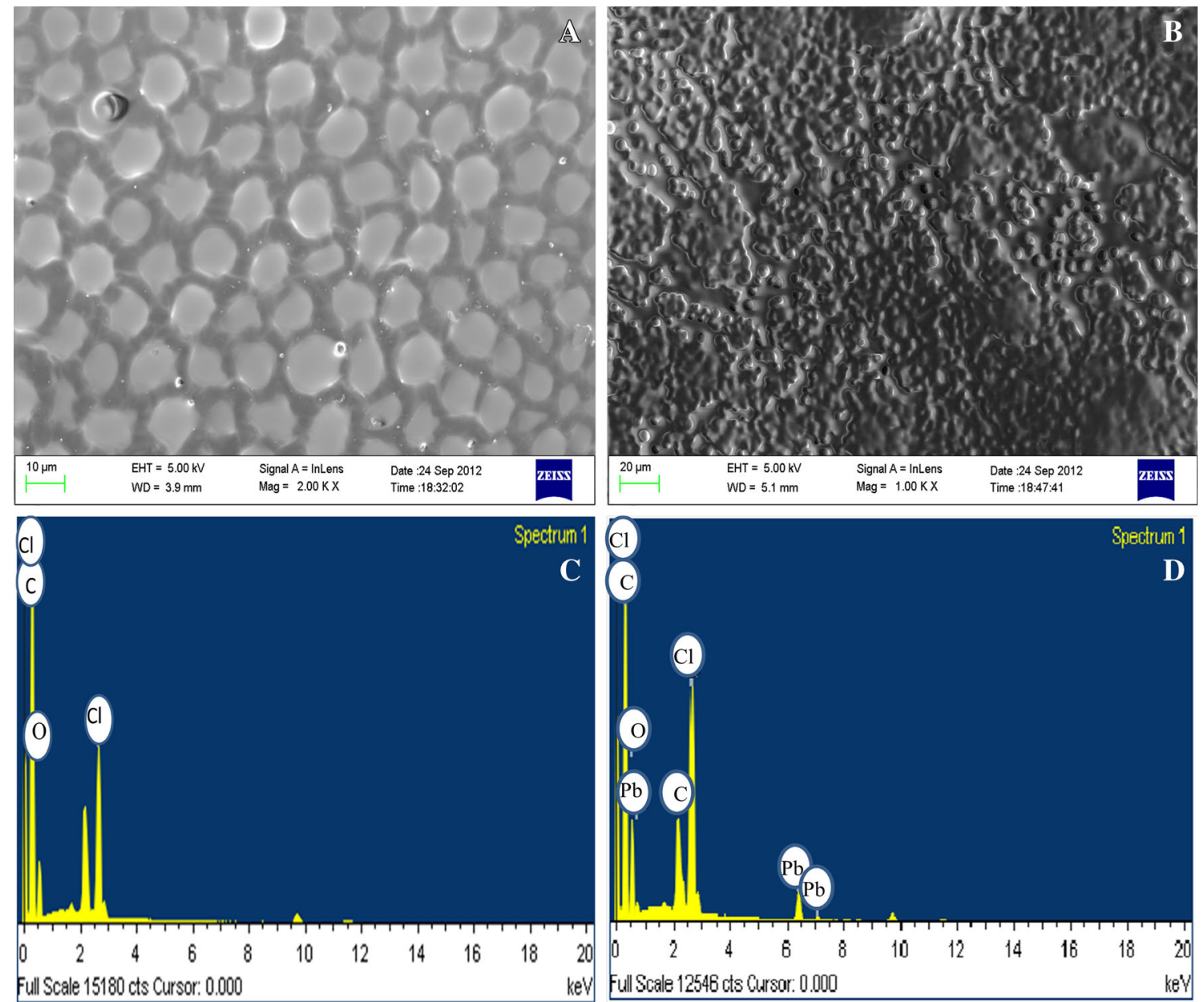

Fig. 2 SEM images of the membrane at different stages $(\times 1,000)(\mathbf{a})$ PVC membrane $(\mathbf{b})$ PVC/2-NPOE/ionophore membrane and EDX spectra of (c) PVC/2-NPOE membrane without ionophore (d) PVC/2-NPOE membrane with ionophore conditioned in $10^{-2} \mathrm{M} \mathrm{Pb}(\mathrm{II})$ ions for $24 \mathrm{~h}$ 
determines the distribution of carrier as well as metal ion in the polymer matrix that further affect the response characteristics of proposed sensor. With the development of the new surface analysis technique such as scanning electron microscopy (SEM), it is possible to image the surfaces of some non-conducting sample like PVC membrane to distinguish their surface characteristics in order to investigate the surface morphology of $\mathrm{Pb}(\mathrm{II})$ ion-selective membrane. SEM studies were carried out at different magnification. In Fig. 2, image (a) shows the pure PVC membrane exhibited high porous polymer matrix with a relatively uniform pore size in the sub-micrometer range and physically tight structure in the polymer matrix. The image (b) shows that after the addition of 2-NPOE and NS derivative as ionophore, the pores of pure PVC membrane vanishes and a new layer has been formed that has tiny channel to diffuse the $\mathrm{Pb}(\mathrm{II})$ ions. In order to check the selectivity of the NS derivative toward the $\mathrm{Pb}$ (II) ions, the EDX spectra of the conditioned membranes 2-NPOE-PVC membrane without ionophore (image c) and 2-NPOE-PVC membrane with ionophore (image d) in $1.0 \times 10^{-2} \mathrm{M} \mathrm{Pb}$ (II) solution have been taken. Its clear from image (c) that no $\mathrm{Pb}$ (II) content has been detected in the PVC/2-NPOE membrane without ionophore. It shows only PVC membrane constituents such as $\mathrm{C}, \mathrm{O}$, and $\mathrm{Cl}$. But on the other hand, the PVC/2-NPOE membrane with ionophore (image d) shows PVC membrane constituents $\mathrm{C}, \mathrm{O}, \mathrm{Cl}$ as well as $\mathrm{Pb}$ (II) content. These results reveal that the ionophore is efficient and selective to form the complex with $\mathrm{Pb}(\mathrm{II})$.

Potentiometric response for multiple ions using SCPEDOT/PSS-CGEs

In the preliminary experiments, PVC-based SC-PEDOT/ PSS-CGEs for a wide variety of mono-, di-, and trivalent metal ions were prepared by incorporating $40.0 \mathrm{mg} \mathrm{PVC}$, $80.0 \mathrm{mg}$ 2-NPOE as plasticizer, $2.0 \mathrm{mg} \mathrm{KTpClB}$ as additive, and $3.0 \mathrm{mg}$ of NS derivative as ionophore. These SCPEDOT/PSS-CGEs were conditioned in respective metal ion solution at $1.0 \times 10^{-2} \mathrm{M}$ concentration for $72 \mathrm{~h}$, and its potential response was noted over the concentration range of $1.0 \times 10^{-1}-1.0 \times 10^{-9} \mathrm{M}$ for different metal ions. It can be seen from Figure (online resource 2) that except $\mathrm{Pb}$ (II) ions, the slopes for the linear part of the response of different SC-PEDOT/PSS-CGEs for most of tested cations are much lower than as expected by Nernstian equation. Results obtained from conductivity, SEM and potentiometry techniques indicate that NS derivative has preferential affinity towards $\mathrm{Pb}(\mathrm{II})$ ions and can be employed as an ionophore for the development of $\mathrm{Pb}$ (II) solid-contact ion-selective electrodes.

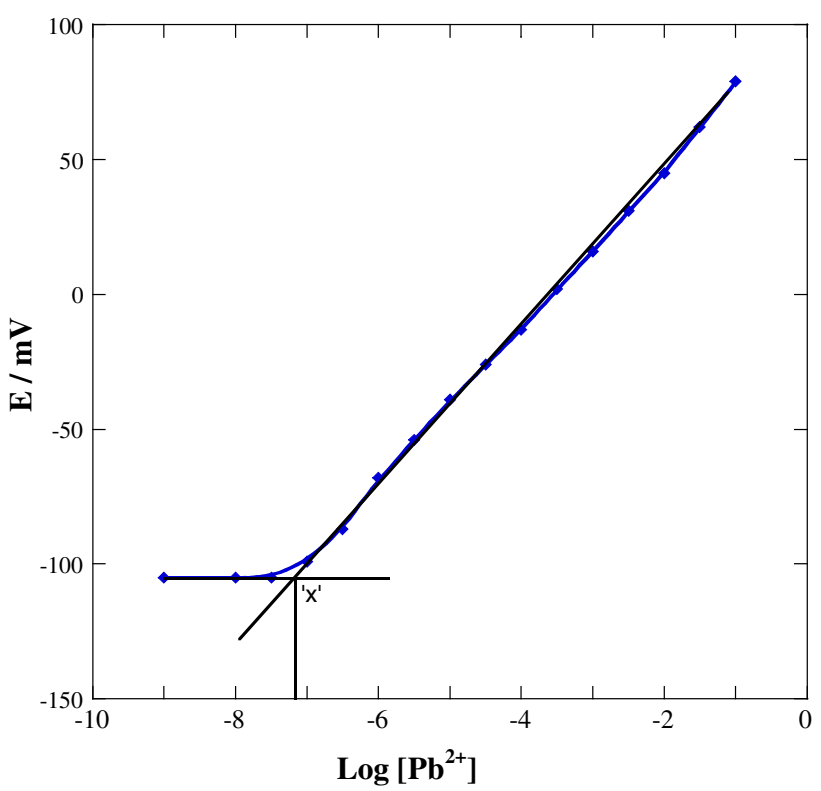

Fig. 3 Potential response curves of NS derivative based SC-PEDOT/ PSS-CGE- 1 for $\mathrm{Pb}$ (II) ions

Potentiometric response for $\mathrm{Pb}(\mathrm{II})$ ions using SCPEDOT/PSS-CGEs

On the basis of results obtained from preliminary investigations on NS derivative, it was decided to employ NS derivative as an ion carrier for the development of $\mathrm{Pb}(\mathrm{II})$ solid-contact electrodes. Potentiometric response curve and composition for the SC-PEDOT/PSS-CGE-1 have been shown in Fig. 3 and Table 2, respectively. Polymeric based SC-PEDOT/PSS-CGE-1 for Pb(II) containing NS derivative as ionophore exhibited Nernstian slope of $29.21 \mathrm{mV} /$ decade over wide concentration range of $1.0 \times 10^{-1}$ $1.0 \times 10^{-7} \mathrm{M}$ with lower detection limit (LOD) of $5.62 \times 10^{-8} M(56.2 \mathrm{~nm})$ (' $x$ ' in Fig. 3).

\section{Effect of additive content}

The properties of ion-selective electrodes (ISEs) based on neutral ionophores are strongly influenced by the ionic sites in their membranes. Although neutral carrier-based ISEs membranes may work properly even when they contain only a small amount of ionic sites, the addition of a salt of lipophilic ion is advisable and beneficial for various other reasons as well. Their main function is to render the ionselectivity and to reduce the bulk membrane impedence (Diaz and Bakker 2001). In our study, potassium tetrakis(4chlorophenyl)borate (KTpClB) was incorporated as an additional membrane component. It is clear from Table 2 that as we reduce the amount of KTpClB from SC-PEDOT/ 
Table 2 Composition and response characteristics of NS derivative based SC-PEDOT/PSS-CGEs for Pb(II) ions

\begin{tabular}{llllllll}
\hline $\begin{array}{l}\text { S. no } \\
\text { SC-PEDOT } \\
\text { /PSS- }\end{array}$ & PVC $(\mathrm{mg})$ & $\begin{array}{l}\text { Plasticizer } \\
(\mathrm{mg})\end{array}$ & $\begin{array}{l}\text { KTpClB } \\
(\mathrm{mg})\end{array}$ & $\begin{array}{l}\text { Ionophore } \\
(\mathrm{mg})\end{array}$ & $\begin{array}{l}\text { Linear } \\
\text { range }(\mathrm{M})\end{array}$ & $\begin{array}{l}\text { Detection } \\
\text { limit }(\mathrm{M})\end{array}$ & $\begin{array}{l}\text { Slope } \\
(\mathrm{mV} / \mathrm{dec} .) \\
\pm 0.01\end{array}$ \\
\hline CGE-1 & 40.0 & 80.0 (2-NPOE) & 2.0 & 3.0 & $1.0 \times 10^{-1}-1.0 \times 10^{-7}$ & $5.62 \times 10^{-8}$ & 29.21 \\
CGE-2 & 40.0 & 80.1 (2-NPOE) & 1.0 & 3.1 & $1.0 \times 10^{-1}-5.0 \times 10^{-7}$ & $2.09 \times 10^{-7}$ & 24.14 \\
CGE-3 & 40.6 & 80.2 (2-NPOE) & 0.0 & 3.0 & $5.0 \times 10^{-2}-5.0 \times 10^{-6}$ & $9.20 \times 10^{-5}$ & 11.61 \\
CGE-4 & 41.0 & 80.0 (2-NPOE) & 2.1 & 5.0 & $1.0 \times 10^{-1}-5.0 \times 10^{-7}$ & $1.07 \times 10^{-7}$ & 35.39 \\
CGE-5 & 40.6 & 81.0 (2-NPOE) & 2.2 & 1.0 & $1.0 \times 10^{-1}-1.0 \times 10^{-6}$ & $7.92 \times 10^{-6}$ & 17.12 \\
CGE-6 & 40.5 & 81.0 (2-NPOE) & 1.9 & 0.0 & $1.0 \times 10^{-1}-1.0 \times 10^{-4}$ & $6.95 \times 10^{-4}$ & 8.21 \\
CGE-7 & 39.8 & 80.2 (2-NPOE) & 2.0 & 7.0 & $1.0 \times 10^{-1}-1.0 \times 10^{-5}$ & $2.81 \times 10^{-6}$ & 46.39 \\
CGE-8 & 40.8 & 79.7 (DOS) & 2.2 & 5.1 & $1.0 \times 10^{-2}-1.0 \times 10^{-6}$ & $5.33 \times 10^{-5}$ & 19.26 \\
CGE-9 & 40.2 & 79.9 (TBP) & 2.1 & 5.1 & $1.0 \times 10^{-2}-1.0 \times 10^{-6}$ & $9.0 \times 10^{-6}$ & 22.91 \\
CGE-10 & 41.0 & 80.4 (DOP) & 1.9 & 4.8 & $5.0 \times 10^{-2}-5.0 \times 10^{-7}$ & $7.79 \times 10^{-7}$ & 15.78 \\
CGE-11 & 40.0 & 80.8 (DOA) & 1.8 & 4.9 & $1.0 \times 10^{-1}-5.0 \times 10^{-6}$ & $1.11 \times 10^{-6}$ & 20.50 \\
CGE-12 & 40.8 & 80.3 (DBP) & 2.0 & 5.2 & $1.0 \times 10^{-2}-5.0 \times 10^{-6}$ & $4.29 \times 10^{-6}$ & 12.36 \\
\hline
\end{tabular}

PSS-CGE-1 (2.0 mg) to SC-PEDOT/PSS-CGE-3 (0.0 mg), the Nernstian slopes and linear range decrease where detection limits change from $5.62 \times 10^{-8}$ to $9.20 \times 10^{-5} \mathrm{M}$. So, it revealed that $2.0 \mathrm{mg}$ amount of $K T p C l B$ was found to be optimum for the smooth functioning of SC-PEDOT/PSS-CGE-1 for Pb(II) ions.

\section{Effect of ionophore}

Effect of ionophore content on the response characteristics of $\mathrm{Pb}(\mathrm{II})$ solid-contact ISEs incorporating NS derivative as an ion carrier was studied by preparing membrane electrodes SC-PEDOT/PSS-CGE-1 (3.0 mg), SC-PEDOT/PSS-CGE-4 (5.0 mg), SC-PEDOT/PSSCGE-5 (1.0 mg), and SC-PEDOT/PSS-CGE-7 (7.0 mg) were prepared by using different amount of NS derivative as ionophore. Composition and response characteristics for these electrodes have been given in Table 2. The SC-PEDOT/PSS-CGE-1 containing $3.0 \mathrm{mg}$ of ionophore exhibited Nernstian slope of $29.21 \mathrm{mV} /$ decade over wide concentration range of $1.0 \times 10^{-1}$ $1.0 \times 10^{-7} \mathrm{M}$ for $\mathrm{Pb}(\mathrm{II})$ ions with lower detection limit of $5.62 \times 10^{-8} \mathrm{M}$ (56.2 nM). SC-PEDOT/PSS-CGE-5 containing ionophore $1.0 \mathrm{mg}$ of ionophore exhibited subNernstian slope of $17.12 \mathrm{mV} /$ decade for $\mathrm{Pb}$ (II) ions over concentration range of $1.0 \times 10^{-1}-1.0 \times 10^{-6} \mathrm{M}$ with the detection limit of $7.92 \times 10^{-6} \mathrm{M}$. On the other hand, SCPEDOT/PSS-CGE-4 and PSS-CGE-7 containing 5.0 and $7.0 \mathrm{mg}$ of ionophore shows super-Nernstian slopes of 35.39 and $46.39 \mathrm{mV} / \mathrm{dec}$ ade for $\mathrm{Pb}(\mathrm{II})$ ions over concentration ranges of $1.0 \times 10^{-1}-5.0 \times 10^{-7} \mathrm{M}$ and $1.0 \times 10^{-1}$
$1.0 \times 10^{-5} \mathrm{M}$ with the detection limits of $1.07 \times 10^{-7}$ and $2.81 \times 10^{-6} \mathrm{M}$, respectively. The performance of membrane without ionophore (dummy membrane) was also investigated, and sub-Nernstian slope $(8.21 \mathrm{mV} /$ decade $)$ was observed (SC-PEDOT/PSS-CGE-6) with narrow concentration range $\left(1.0 \times 10^{-1}-1.0 \times 10^{-4} \mathrm{M}\right)$ and high detection limit $\left(6.95 \times 10^{-4} \mathrm{M}\right)$. This clearly demonstrated the need of carrier in the fabrication of $\mathrm{Pb}$ (II) ISEs. So, the best result was obtained with SC-PEDOT/PSS-CGE-1 containing $3.0 \mathrm{mg}$ content of ionophore.

\section{Effect of plasticizer}

Choosing an appropriate plasticizer is essential for the construction of an ion-selective electrode with high analytical performances, such as Nernstian slope, selectivity, fast response, long life, and lower detection limit (Zhang et al. 2000). Compatibility with polymer and electrodic component (ionophore), low solubility in aqueous solution, low viscosity, low cost, and low toxicity are the desirable properties of the plasticizers (O'Rourke et al. 2011). Plasticizers embedded itself between chains of the polymer and spaces them apart, so free volume increases which is responsible for the flexibility and durability of the membrane. In the present work, six plasticizers of different dielectric constants $(\varepsilon)$ and chemical structures such as 2-NPOE, DOS, TBP, DOP, DOA, and DBP were studied on $\mathrm{Pb}$ (II) ISEs based upon ionophore NS derivative. From the data in Table 2, it is clear that 2-NPOE is proved to be most suitable plasticizer, which shows Nernstian slope of $29.21 \mathrm{mV} /$ decade with detection limit of $5.62 \times 10^{-8} \mathrm{M}$ 


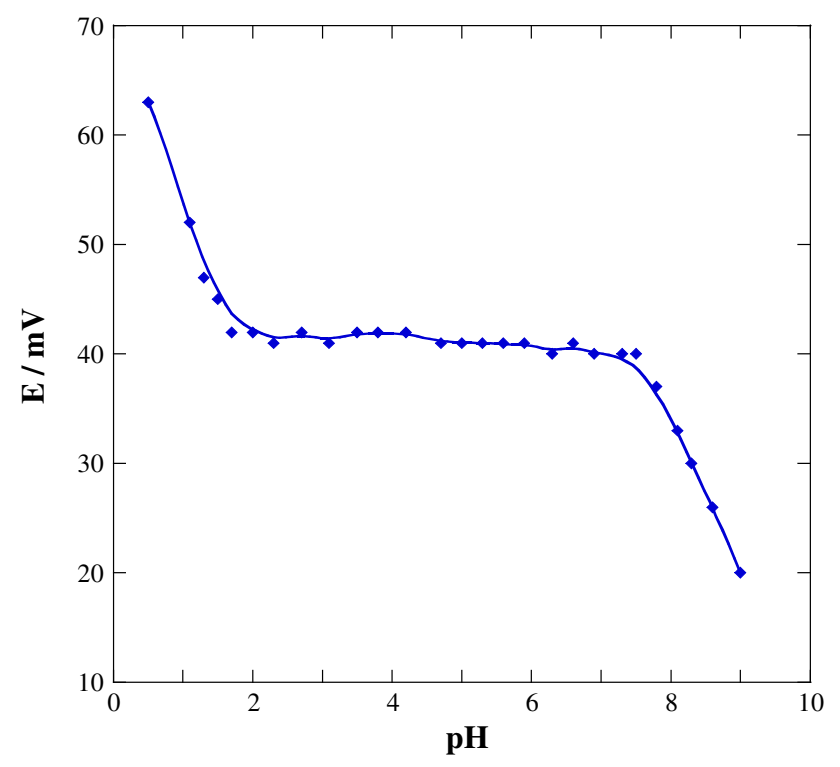

Fig. 4 Effect of $\mathrm{pH}$ on potential response of NS derivative based SCPEDOT/PSS-CGE-1 for $\mathrm{Pb}(\mathrm{II})$ ions

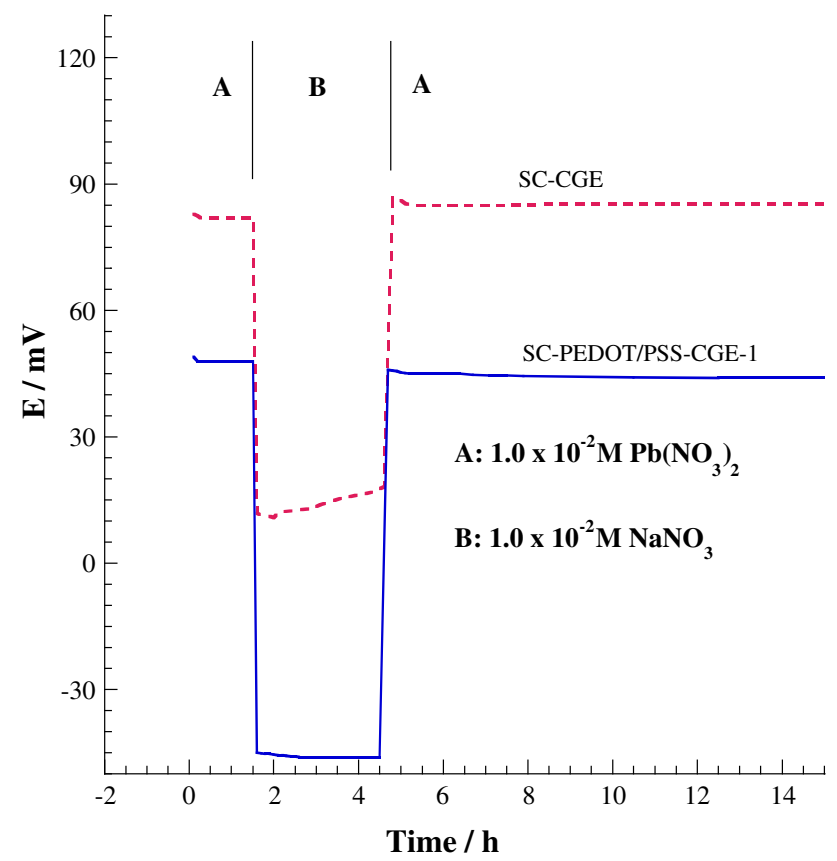

Fig. 5 Water layer test of $\mathrm{Pb}(\mathrm{II})$-selective electrodes with $\mathrm{SC}$ PEDOT/PSS-CGE- 1 and SC-CGE recorded in $(A) 1.0 \times 10^{-2} \mathrm{M}$ of $\mathrm{Pb}\left(\mathrm{NO}_{3}\right)_{2}(B) 1.0 \times 10^{-2} \mathrm{M} \mathrm{NaNO}_{3}$

(SC-PEDOT/PSS-CGE-1). The plasticizers such as DOS (4.6), TBP (3.5), DOP (5.1), DOA (4.0), and DBP (6.4) \{SC-PEDOT/PSS-CGEs 8-12\} exhibited sub-Nernstian slopes of 19.26, 22.91, 15.78, 20.50, and $12.36 \mathrm{mV} /$ decade, respectively. All of these imply that the plasticizer 2-NPOE with high dielectric constant $(\varepsilon=24)$ ) showed best response characteristics seem to be favorable environments for the complexation between $\mathrm{Pb}(\mathrm{II})$ and NS derivative, whereas the plasticizers with moderate or lower dielectric constants were not considered so appropriate for construction of $\mathrm{Pb}$ (II) SC-PEDOT/PSS-CGE-1. So, 2-NPOE was selected as the plasticizer for further investigation.

Influence of $\mathrm{pH}$ on response characteristics of SCPEDOT/PSS-CGE-1

The potential response of ISEs is affected by the $\mathrm{pH}$ of analyte ion solution employed. The $\mathrm{pH}$ dependent of SCPEDOT/PSS-CGE-1 has been tested over the $\mathrm{pH}$ range of $1.0-9.0$ with $1.0 \times 10^{-2} \mathrm{M} \mathrm{Pb}$ (II) ions solution. The $\mathrm{pH}$ values were adjusted using con. nitric acid or hexamine and potential was measured after each addition. The potential response remains constant over $\mathrm{pH}$ range of $2.0-7.0$ as shown in Fig. 4. The noticeable decrease in potential response observed at lower $\mathrm{pH}$ can be due to interference of hydrogen ions, and potential response decreasing sharply at higher $\mathrm{pH}$ may be due to the formation of some hydroxyl complexes of $\mathrm{Pb}$ (II) ions in solution from hydrolysis of $\mathrm{Pb}$ (II) nitrate salt.

Aqueous layer test: potential stability of $\mathrm{Pb}$ (II) SCPEDOT/PSS-CGE-1

It has been realized that the thin water layer can form between the PVC membrane and its solid contact. The stability of the proposed electrode was tested using the protocol developed by Fibbioli et al. (2000). The studied electrode modified with PEDOT/PSS was initially immersed in $1.0 \times 10^{-2} \mathrm{M} \mathrm{Pb}\left(\mathrm{NO}_{3}\right)_{2}$ solution. After $1.5 \mathrm{~h}$, the solution was changed to $1.0 \times 10^{-2} \mathrm{M} \mathrm{NaNO}_{3}$ solution (diverse ion). After 3-h diverse, ion solution was replaced by again $1.0 \times 10^{-2} \mathrm{M} \mathrm{Pb}\left(\mathrm{NO}_{3}\right)_{2}$ solution. Its clear from Fig. 5 that no potential drift was observed for $\mathrm{Pb}$ (II) SC-PEDOT/PSS-CGE-1 upon changing the analyte in sample solution from primary ions to the diverse ions and again to primary ions. On the other hand, at similar conditions, the electrode (SC-CGE) without PEDOT/PSS polymer exhibits significant potential drift as shown in Fig. 5. So, these results revealed that no aqueous layer was formed in between membrane and solid contact, when the solid contact was modified with PEDOT/PSS polymer. 
Table 3 Selectivity coefficients of various diverse ions (B) for NS derivative based SC-PEDOT/PSS-CGE-1

\begin{tabular}{llll}
\hline $\begin{array}{l}\text { Diverse } \\
\text { ions (B) }\end{array}$ & $\left(\log K_{\mathrm{Pb}^{2+}, \mathrm{B}}^{\text {Pot. }} \pm \mathrm{SD}\right)^{\mathrm{b}}$ & $\begin{array}{l}\text { Diverse } \\
\text { ions (B) }\end{array}$ & $\left(\log K_{\mathrm{Pb}^{2+}, \mathrm{B}}^{\mathrm{Pot}} \pm \mathrm{SD}\right)^{\mathrm{b}}$ \\
\hline $\mathrm{Co}^{2+}$ & $-3.05 \pm 0.06$ & $\mathrm{Mg}^{2+}$ & $-4.20 \pm 0.03$ \\
$\mathrm{Hg}^{2+}$ & $-2.53 \pm 0.02$ & $\mathrm{Ag}^{+}$ & $-3.39 \pm 0.08$ \\
$\mathrm{Cd}^{2+}$ & $-3.94 \pm 0.07$ & $\mathrm{Li}^{+}$ & $-3.49 \pm 0.09$ \\
$\mathrm{Cu}^{2+}$ & $-2.98 \pm 0.07$ & $\mathrm{Ca}^{2+}$ & $-4.10 \pm 0.08$ \\
$\mathrm{Zn}^{2+}$ & $-4.25 \pm 0.05$ & $\mathrm{~K}^{+}$ & $-4.20 \pm 0.03$ \\
$\mathrm{Fe}^{3+}$ & $-3.15 \pm 0.04$ & $\mathrm{Na}^{+}$ & $-4.36 \pm 0.06$ \\
$\mathrm{NH}_{4}{ }^{+}$ & $-3.00 \pm 0.05$ & & \\
\hline
\end{tabular}

${ }^{\mathrm{b}}$ Mean value \pm standard deviation (three measurement)

Response, life time, reproducibility of proposed $\mathrm{Pb}(\mathrm{II})$

SC-PEDOT/PSS-CGE-1

The response time of an ISE is the average time required for attaining the equilibrium value of the potential when dipped in successive $\mathrm{Pb}$ (II) ion solution, each having the ten-fold difference in concentration. To measure the dynamic response time of proposed SC-PEDOT/PSS-CGE-1, the $\mathrm{Pb}$ (II) ions concentration of the test solution was successively changed from lower $\left(1.0 \times 10^{-5} \mathrm{M}\right)$ to higher $\left(1.0 \times 10^{-1} \mathrm{M}\right)$. A potential versus time trace plot for SCPEDOT/PSS-CGE-1 is shown in Figure (online resource 3). It is evident from Figure that potential response reached the equilibrium in very short time of $<10 \mathrm{~s}$. The potential generated by the developed sensor remain stable for more than 4 min after which divergence was recorded. Short response time of SC-PEDOT/PSS-CGE-1 may be due to high electric conductivity of the conducting polymer casted on the graphite rod. SC-PEDOT/PSS-CGE-1 can be used over the period of 4 months without any significant change in Nernstian slope, lower detection limit, linear range, and response time. During this period, slope of electrodes shows only slight change from 29.21 to $27.96 \mathrm{mV} /$ decade for SCPEDOT/PSS-CGE-1 (online resource 4) and that after more than 4 months time, the selectivity and sensitivity of SCPEDOT/PSS-CGE-1 get degrading. It may be due to leaching out of the ionophore from the membrane.

\section{Selectivity of proposed $\mathrm{Pb}$ (II) SC-PEDOT/PSS-CGE-1}

The selectivity coefficient $(K)$ is the very important source of information concerning interference on the electrode response. In the present work, fixed interference method (FIM) based on semi-empirical Nikolsky-Eiseman equation was employed to determine logarithmic selectivity coefficient $\left(\log K_{\mathrm{A}, \mathrm{B}}^{\text {Pot. }}\right)$ of proposed Pb(II) SC-PEDOT/PSS-CGE-1.

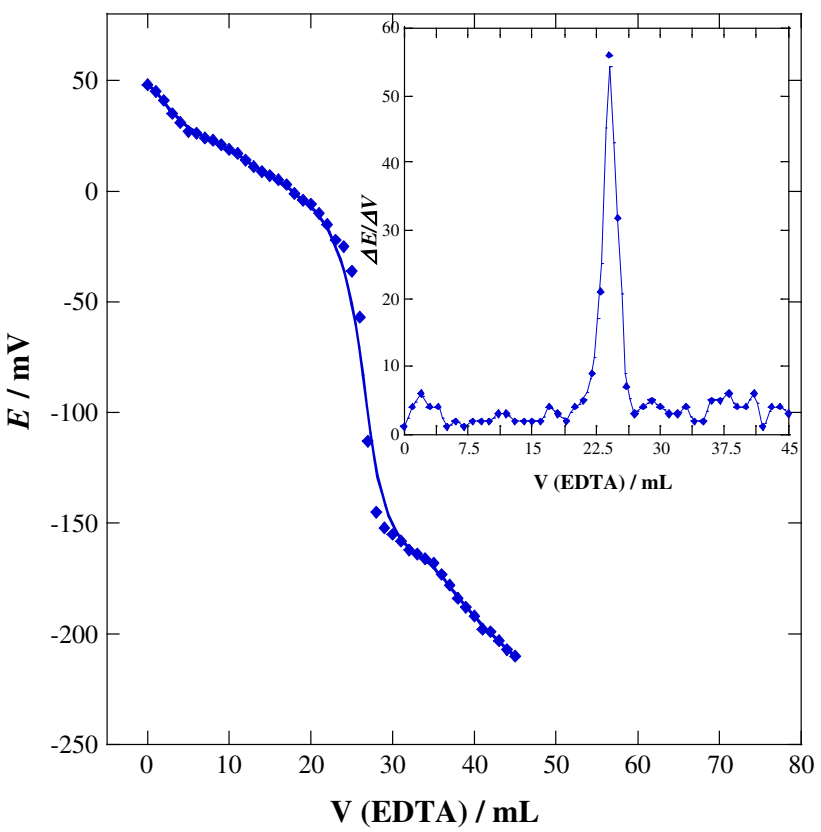

Fig. 6 Potentiometric titration of $1.0 \times 10^{-2} \mathrm{M} \mathrm{Pb}$ (II) solution with $1.0 \times 10^{-2} \mathrm{M}$ EDTA using SC-PEDOT/PSS-CGE-1 based on NS derivative

$K_{\mathrm{A}, \mathrm{B}}^{\mathrm{Pot}}=\left(\frac{a_{\mathrm{A}}}{a_{\mathrm{B}}}\right)^{\frac{\frac{1}{\mathrm{~A}}_{\mathrm{B}}}{\frac{\mathrm{B}}{\mathrm{B}}}}$

Emf of the cell is measured for solution containing constant activity $\left(a_{\mathrm{B}}\right)$ of diverse ions with charge $Z_{\mathrm{B}}$ and varying activity $\left(a_{\mathrm{A}}\right)$ of the primary ions with charge $Z_{\mathrm{A}}$.

The values of logarithmic selectivity coefficients $\left(\log K_{\mathrm{Pb}^{2+}, \mathrm{B}}^{\mathrm{Pot}}\right)$ obtained by FIM for proposed electrode are shown in Table 3. As it is evident from Table 3, the SCPEDOT/PSS-CGE-1 is very selective to $P b(I I)$ ions over all diverse ions, but among all of them, $\mathrm{Hg}$ (II) ions have high selectivity coefficient $\left(\log K_{\mathrm{Pb}^{2+}, \mathrm{Hg}^{2+}}^{\mathrm{Pot}}=-2.53\right)$ which indicate the tolerance level of the proposed SC-PEDOT/ PSS-CGE-1 toward $\mathrm{Hg}$ (II) is low as compared to other diverse metal ions. Taking account the lower detection limit and response time, the observed tolerable $\mathrm{Hg}$ (II) concentration was up to $1.0 \times 10^{-2} \mathrm{M}$. Below this concentration, the $\operatorname{Hg}(\mathrm{II})$ ions show no interference in the normal functioning of SC-PEDOT/PSS-CGE-1.

\section{Analytical applications}

Due to the high selectivity toward $\mathrm{Pb}$ (II) ion, $\mathrm{Pb}$ (II)-PEDOT/PSS-CGE-1 was employed to monitor $\mathrm{Pb}$ (II) ion concentration in various samples, while AAS and volumetric methods were used as reference methods. 
Table 4 Estimation of $\mathrm{Pb}(\mathrm{II})$ ions in various sample matrices by SC-PEDOT/PSS-CGE-1

\begin{tabular}{|c|c|c|c|c|c|}
\hline \multirow[t]{2}{*}{ Sample } & \multicolumn{5}{|c|}{$(\mathrm{Pb}(\mathrm{II}) \text { content in samples } \pm \mathrm{SD})^{\mathrm{c}} \mathrm{M}$} \\
\hline & $\mathrm{Pb}(\mathrm{II})$ added & $\begin{array}{l}\text { Ion-selective electrode } \\
\text { (SC-PEDOT/PSS-CGE-1) }\end{array}$ & $\begin{array}{l}\text { Atomic absorption } \\
\text { spectrophotometry } \\
\text { (AAS) }\end{array}$ & Volumetric method & $\begin{array}{l}\text { Percentage compatibility (SC- } \\
\text { PEDOT/PSS-CGE-1 with AAS) }\end{array}$ \\
\hline Tap water & $3.50 \times 10^{-2}$ & $3.45 \pm 0.04 \times 10^{-2}$ & $3.70 \pm 0.04 \times 10^{-2}$ & $3.20 \pm 0.07 \times 10^{-2}$ & $93.24 \pm 0.04$ \\
\hline Well water & $1.50 \times 10^{-4}$ & $1.61 \pm 0.01 \times 10^{-4}$ & $1.55 \pm 0.06 \times 10^{-4}$ & $1.11 \pm 0.08 \times 10^{-4}$ & $103.24 \pm 0.03$ \\
\hline River water & $4.50 \times 10^{-6}$ & $4.55 \pm 0.07 \times 10^{-6}$ & $4.69 \pm 0.08 \times 10^{-6}$ & - & $97.0 \pm 0.07$ \\
\hline $\begin{array}{l}\text { Industrial } \\
\text { waste } \\
\text { water }\end{array}$ & - & $9.22 \pm 0.02 \times 10^{-5}$ & $8.90 \pm 0.03 \times 10^{-5}$ & - & $103.59 \pm 0.08$ \\
\hline $\begin{array}{r}\text { Lead acid } \\
\text { batteries }\end{array}$ & - & $4.98 \pm 0.05 \times 10^{-4}$ & $4.98 \pm 0.01 \times 10^{-4}$ & $4.70 \pm 0.07 \times 10^{-4}$ & $100.00 \pm 0.08$ \\
\hline $\begin{array}{l}\text { Naga } \\
\text { bhasma }\end{array}$ & - & $5.00 \pm 0.07 \times 10^{-2}$ & $5.25 \pm 0.02 \times 10^{-2}$ & $4.35 \pm 0.08 \times 10^{-2}$ & $95.24 \pm 0.07$ \\
\hline $\begin{array}{l}\text { Basant } \\
\text { kasumkar } \\
\text { ras }\end{array}$ & - & $5.06 \pm 0.06 \times 10^{-4}$ & $4.68 \pm 0.01 \times 10^{-4}$ & $5.20 \pm 0.08 \times 10^{-4}$ & $108.12 \pm 0.04$ \\
\hline $\begin{array}{l}\text { Ekangveer } \\
\text { ras }\end{array}$ & - & $7.96 \pm 0.03 \times 10^{-6}$ & $7.23 \pm 0.04 \times 10^{-6}$ & - & $110.10 \pm 0.03$ \\
\hline
\end{tabular}

${ }^{c}$ Mean value \pm standard deviation (three measurement)

Potentiometric titration

Proposed $\mathrm{Pb}$ (II)-PEDOT/PSS-CGE-1 was found to work well under laboratories conditions. Practical utility of the this electrode was tested by using them as indicator electrode for potentiometric titration of $\mathrm{Pb}(\mathrm{II})$ ion solution $\left(1.0 \times 10^{-2} \mathrm{M}\right)$ with EDTA solution $\left(1.0 \times 10^{-2} \mathrm{M}\right)$, and corresponding titration curve is shown in Fig. 6 . The plot is sigmoid in shape, and the inflexion point of the plot corresponds to 1:1 stoichiometry of EDTA complex, while the potential response after the end point remains almost constant, due to low concentration of free $\mathrm{Pb}$ (II) ions in solution. Therefore, the end point and the amount of $\mathrm{Pb}$ (II) ions in the solution can be accurately determined by extrapolation of the three linear portion of titration plot.

Estimation of $\mathrm{Pb}(\mathrm{II})$ in various sample matrices by $\mathrm{SC}-$ PEDOT/PSS-CGE-1

SC-PEDOT/PSS-CGE-1 has been used to determine the $\mathrm{Pb}$ (II) content in different water samples such as tap, well, river, industrial waste water, lead acid batteries and Indian manufactured ayurvedic medicines. Tap, well, and river water samples were analyzed by SC-PEDOT/PSS-CGE-1 to detect $\mathrm{Pb}$ (II) concentration by using its spiked samples; otherwise, it is very difficult to determine $\mathrm{Pb}$ (II) in these samples. All others samples have been prepared in same way as already used in our laboratory (Mahajan et al. 2013;
Kamal et al. 2014). From the Table 4, it is clear that estimation of $\mathrm{Pb}(\mathrm{II})$ in various sample matrices by using SCPEDOT/PSS-CGE-1 gives compatible result with the AAS and also with volumetric method using EDTA as titrant except those samples where $\mathrm{Pb}$ (II) concentration is lower than $1.0 \times 10^{-5} \mathrm{M}$.

\section{Statistical treatment of SC-PEDOT/PSS-CGE-1 results}

To check the reliability of proposed electrode, the results obtained by SC-PEDOT/PSS-CGE-1 and AAS are statistically compared and it is observed that very satisfactory results have been obtained. Linear regression line of SCPEDOT/PSS-CGE-1 versus AAS yields a correlation of $R=0.999$ (approx. equal to 1) and 7 degree of freedom with comparison line $y=1.05 x+0.012$. It is clear from the value of $R(R=$ correlation coefficient) that regression line was undistinguishable from the theoretical $y=x$ comparison line. Similarly, if the paired Student's $t$ test is performed for SC-PEDOT/PSS-CGE-1 versus AAS, the calculated value of $t$ we get is 1.37 , whereas the tabular $t$ value is 2.365 ( 7 degree of freedom with $95 \%$ confidence level). The calculated $t$ value is less than tabular $t$ value, which demonstrated that there are no significant difference between results obtained with both methods SCPEDOT/PSS-CGE-1 and AAS. So, we can say that results obtained from SC-PEDOT/PSS-CGE-1 are reliable, reproducible, and acceptable. 


\section{Conclusion}

New graphite contact modified with PEDOT/PSS conducting polymer coated with PVC membrane electrode (SC-PEDOT/PSS-CGE-1), which is highly selective to $\mathrm{Pb}$ (II) ions, has been developed using naphthalene-sulfonamide (NS) derivative as electro-active material. It shows Nernstian slope of $29.21 \mathrm{mV} /$ decade and wide concentration range $1.0 \times 10^{-1}-1.0 \times 10^{-7} \mathrm{M}$ with lower detection limit of $5.62 \times 10^{-8} \mathrm{M}(56.2 \mathrm{~nm})$. Its response time is $<10 \mathrm{~s}$ and has ability to work within $\mathrm{pH}$ range of 2.0-7.0. Developed electrode exhibited excellent selectivity, sensitivity, and large concentration range with no interference observed from diverse ions. It is successfully applied as an indicator electrode in potentiometric titration of $\mathrm{Pb}$ (II) ion solution with EDTA. Its high selectivity permits the direct measurement of $\mathrm{Pb}$ (II) ions in different environmental and ayurvedic medicine samples. The reliability of proposed electrode has been checked statistically by using paired Student's $t$ test.

Acknowledgments This paper was financially supported by the Council of Scientific and Industrial Research (CSIR), New Delhi, as a part of project (01)2469/11/EMR-II. One of Authors Ajar Kamal (AK) is thankful to CSIR for award of Senior Research Fellow (SRF).

\section{References}

Abbaspour A, Mirahmadi E, Khalafi-nejad A, Babamohammadi S (2010) A highly selective and sensitive disposable carbon composite PVC-based membrane for determination of lead ion environmental samples. J Hazard Mater 174:656-661

Anastasova S, Radu A, Matzeu G, Zuliani C, Mattinen U (2012) Disposable solid-contact ion-selective electrodes for environmental monitoring of lead with ppb limit-of-detection. Electrochim Acta 73:93-97

Baird C (1999) Environmental chemistry, 2nd edn. W.H. Freeman and company, New York

Bhalla V, Tejpal R, Kumar M (2012) New terphenyl based ensemble for the detection of acetate ions in plasma like system. Dalton Trans 41:403-407

Bobacka J (2006) Conducting polymer-based solid-state ion-selective electrodes. Electroanalysis 18:7-18

Bobacka J, Vaananen V, Lewenstam A, Ivaska A (2004) Influence of anionic additive on $\mathrm{Hg} 2+$ interference on $\mathrm{Ag}+$-ISEs based on $(2,2,2) \mathrm{p}, \mathrm{p}, \mathrm{p}$-cyclophane as neutral carrier. Talanta 63:135-138

Chen L, Zhang J, Zhao W, He X, Liu Y (2006) Double-armed calix[4]arene amide derivatives as ionophores for lead ionselective electrodes. J Electroanal Chem 589:106-111

Chumbimuni-Torres KY, Rubinova N, Radu A, Kubota LT, Bakker E (2006) Solid contact potentiometric sensors for trace level measurements. Anal Chem 78:1318-1322

Diaz MT, Bakker E (2001) Effect of lipophilic ion-exchanger leaching on the detection limit of carrier-based ion selective electrodes. Anal Chem 73:5582-5589
Elmosallamy MAF, Fathy AM, Ghoneim AK (2008) Lead (II) potentiometric sensor based on 1,4,8,11-tetrathiacyclotetradecane neutral carrier and lipophilic additive. Electroanalysis 20:1241-1245

Fibbioli M, Moft WE, Badertscher M, De Rooji N, Pretsch E (2000) Potential drifts of solid-contacted ion-selective electrodes due to zero-current ion fluxes through the sensor membrane. Electroanalysis $12: 1286-1292$

Goyal RN, Gupta VK, Bachheti N (2007) Fullerence- $\mathrm{C}_{60}$-modified electrode as a sensitive voltammetric sensor for detection of nandrolone - an anabolic steroid used in doping. Anal Chim Acta 597:82-89

Goyal RN, Gupta VK, Bachheti N, Sharma RA (2008a) Electrochemical sensor for the determination of dopamine in presence of high concentration of ascorbic acid using a fullerence- $\mathrm{C}_{60}$ coated gold electrode. Electroanalysis 20:757-764

Goyal RN, Gupta VK, Chatterjee S (2008b) Electrochemical oxidation of $2^{\prime}, 3^{\prime}$-dideoxyadenosine at pyrolytic graphite electrode. Electrochim Acta 53:5354-5360

Goyal RN, Gupta VK, Chatterjee S (2008c) Simultaneously determination of adenosine and inosine using single-wall carbon nanotubes modified pyrolytic graphite electrode. Talanta 76:662-668

Goyal RN, Gupta VK, Chatterjee S (2009) A sensitive voltammetric sensor for determination of synthetic corticosteroid triamcinolone, abused for doping. Biosens Bioelectron 24:3562-3568

Gunturu KS, Nagarajan P, Phedran PM, Goodman TR, Hodsdon ME, Strout MP (2011) Ayurvedic herbal medicine and lead poisonin. J Hematol Oncol 4:51-56

Gupta VK, Prasad R, Kumar P, Mangla R (2000) New nickel (II) selective potentiometric sensor based 5,7,12,14-tetramethyldibenzotetraazaanulene in a poly (vinyl chloride) matrix. Anal Chim Acta 420:19-27

Gupta VK, Chandra S, Mangla R (2002) Dicyclohexano-18-crown-6 as active material in PVC matrix membrane for the fabrication of cadmium selective potentiometric sensors. Electrochim Acta 47:1579-1586

Gupta VK, Prasad R, Kumar A (2003) Preparation of ethambutalcopper (II) complex and fabrication of PVC based membrane potentiometric sensor for copper. Talanta 60:149-160

Gupta VK, Chandra S, Lang H (2005) A highly selective mercury electrode based on a diamine donar ligand. Talanta 66:575-580

Gupta VK, Jain AK, Kumar P, Agarwal S, Meheshwari G (2006a) Chromium(III)-selective sensor based on tri-o-thymotide in PVC matrix. Sens Actuators B 113:182-186

Gupta VK, Jain AK, Kumar P (2006b) PVC-based membrane of N, $\mathrm{N}^{\prime}$-dibenzyl-1,4,10,13-tetraoxa-7,16-diazacyclooctadecane as $\mathrm{Pb}$ (II)-selective sensor. Sens Actuators B 120:259-265

Gupta VK, Jain AK, Maheshwari G, Lang H, Ishtaiwi Z (2006c) Copper(II)-selective potentiometric sensors based on porphyrins in PVC matrix. Sens Actuators B 117:99-106

Gupta VK, Singh AK, Mehtab S, Gupta B (2006d) A cobalt (II)selective PVC membrane based on a Schiff base complex of N, $\mathrm{N}^{\prime}$-bis(salicylidene)-3,4-diaminotolune. Anal Chim Acta 566:5-10

Gupta VK, Singh AK, Al khayat M, Gupta B (2007) Neutral carriers based polymeric membrane electrodes for selective determination of mercury (II). Anal Chim Acta 590:81-90

Gupta VK, Ganjali MR, Norouzi P, Khani H, Nayak A, Agarwal S (2011a) Electrochemical analysis of some toxic metals by ionselective electrodes. Crit Rev Anal Chem 41:282-313

Gupta VK, Jain R, Radhapyari K, Jadon N, Agarwal S (2011b) Voltammetric techniques for the assay of pharmaceutical-a review. Anal Biochem 408:179-196 
Gupta VK, Nayak A, Agarwal S, Singhal B (2011c) Recent advances on potentiometric membrane sensors for pharmaceutical analysis. Comb Chem High Throughput Screen 14:284-302

Gupta VK, Singh LP, Singh R, Upadhyay N, Kaur SP, Sethi B (2012) A novel copper (II) selective sensor based on dimethyl 4,4'(ophenylene)bis(3-thioallophanate) in PVC matrix. J Mol Liq 174:11-16

Gupta VK, Sethi B, Sharma RA, Agarwal S, Bharti A (2013) Mercury selective potentiometric sensor based on low rim functionalized thiacalix[4]-arene as a cation receptor. J Mol Liq 177:114-118

Guzinski M, Lisak G, Sokalski T, Bobacka J, Ivaska A, Bochenska M, Lewenstam A (2013) Solid-contact ion-selective electrodes with highly selective thioamide derivative of p-tert-butylcalix[4]arene for the determination of lead (II) in environmental samples. Anal Chem 85:1551-1561

Huang MR, Rao XW, Li XG, Ding YB (2011) Lead ion-selective electrodes based on polyphenylenediamine as unique solid ionophores. Talanta 85:1575-1584

Jain AK, Gupta VK, Singh LP (2006) A comparative study of $\mathrm{Pb}^{2+}$ selective sensors based on derivatized tetrapyrazole and calix[4]arenes receptors. Electrochim Acta 51:2547-2553

Kamal A, Kumar N, Bhalla V, Kumar M, Mahajan RK (2014) Rhodamine-dimethyliminocinnamyl based electrochemical sensors for selective detection of iron (II). Sens Actuators B 190:127-133

Kazemi SY, Shamsipur M, Sharghi H (2009) Lead-selective poly(vinyl chloride) electrodes based on some synthesized benzo-substituted macrocyclic diamides. J Hazard Mater 172:68-73

Konopka A, Sokalski T, Michalska A, Lewenstam A, Maj-Zurawska M (2004) Factors affecting the potentiometric response of allsolid-state solvent polymeric membrane calcium-selective electrode for low-level measurement. Anal Chem 76:6410-6418

Li XG, Ma XL, Huang MR (2009) Lead (II) ion-selective electrode based on polyaminoanthraquinone particle with intrinsic conductivity. Talanta 78:498-505

Lindner E, Gyurcsanyi RE (2009) Quality control criteria for solidcontact, solvent polymeric membrane ion-selective electrodes. J Solid State Electrochem 13:51-68

Lisak G, Bobacka J, Lewenstam A (2012) Recovery of nanomolar detection limit of solid-contact lead (II)-selective electrodes by electrode conditioning. J Solid State Electrochem 16:2983-2991

Mahajan RK, Kamal A, Kumar N, Bhalla V, Kumar M (2013) Selective sensing of mercury (II) using PVC based membranes incorporating recently synthesized 1,3 alternate thiacalixcrown ionophore. Environ Sci Pollut Res 20:3086-3097

Mi Y, Bakker E (1999) Determination of complex formation constants of lipophillic neutral ionophores in solvent polymeric membranes with segmented sandwich membranes. Anal Chem 71:5279-5287

Michalska A (2006) Optimizing the analytical performance and construction of ion-selective electrodes with conducting polymer-based ion-to-electron transducers. Anal Bioanal Chem 384:391-406

Michalska A, Wojciechowski M, Bulska E, Mieczkowski J, Maksymiuk K (2009) Poly(n-butyl acylate) based lead (II) selective electrodes. Talanta 79:1247-1251

Mobin SM, Sanghavi BJ, Srivastva AK, Mathur P, Lahiri GK (2010) Biomimetic sensor for certain phenols employing a copper(II) complex. Anal Chem 82:5983-5992

O'Rourke M, Duffy N, De Marco R, Potter I (2011) Electrochemical impedence spectroscopy - a simple method for the characterization of polymer inclusion membranes containing aliquant 336 . Membranes 1:132-148
Ochoa GC, Cordero JCA (2010) Effect of membrane composition and thickness on the behavior of solid contact ion selective electrodes for $\mathrm{Pb}^{2+}$ using diazadibenzo-18-crown-6 ether as ionophore. ECS Trans 29:361-368

Paciorek R, Van der Wal PD, de Rooij NF, Maj-Zurawska M (2003) Optimization of the composition of interfaces in miniature planer chloride electrodes. Electroanalysis 15:1314-1318

Qin Y, Mi Y, Bakker E (2000) Determination of complex formation constants of 18 neutral alkali and alkaline earth metal ionophores in poly(vinyl chloride) sensing membranes plasticized with bis(2-ethylhexyl)sebacate and o-nitrophenyloctyl ether. Anal Chim Acta 421:207-220

Rong HM, Li GG, Ying SF, Gui LX (2012) Development of potentiometric lead ion sensors based on ionophores bearing oxygen/sulfur-containing functional groups. Chin J Anal Chem 40:50-58

Sanghavi BJ, Mobin SM, Matur P, Lahiri GK, Srivastava AK (2013) Biomimetric sensor for certain catecholamines employing copper (II) complex and silver nanoparticle modified glassy carbon paste electrode. Biosensor Bioelectron 39:124-132

Sanghavi BJ, Kalabate PK, Karna SP, Shrivastava AK (2014) Voltammetric determination of sumatriptan based on a grapheme/gold nanoparticle/Nafion composite modified glassy carbon electrode. Talanta 120:1-9

Saper RB, Phillips RS, Sehgal A, Khouri N, Davis RB, Paquin J, Thuppil V, Kales SN (2008) Lead, mercury, and arsenic in USand Indian-manufactured ayurvedic medicines sold via the internet. JAMA 300:915-923

Shamsipur M, Ganjali MR (1997) Complex formation of some anilinium ion derivatives with 18-crown-6, 1, 10-diaza-18crown-6 and cryptand C222 in acetonitrile, dimethylformamide and their 1:1 mixture. J Incl Phenom 28:315-323

Singh AK, Singh P (2010) Determination of cerium ion by polymeric membrane and coated graphite electrode based on novel armed macrocycle. Anal Chim Acta 675:170-180

Soleymanpour A, Shafaatian B, Kor K, Hasaninejad AR (2012) Coated wire lead (II)-selective electrode based on a Schiff base ionophore for low concentration measurements. Monatsh Chem 143:181-188

Srivastava SK, Gupta VK, Jain S (1995) Determination of lead using a poly(vinyl chloride)-based crown ether membrane. Analyst 120:495-498

Sutter J, Radu A, Peper S, Bakker E, Pretsch E (2004) Solid-contact polymeric membrane electrodes with detection limits in the subnanomolar range. Anal Chim Acta 523:53-59

Vazquez M, Danielesson P, Bobacka J, Lewenstam A, Ivaska A (2004) Solution-cast films of poly(3,4-ethylenedioxythiophane) as ion-to-electron transducers in all-solid-state ion-selective electrodes. Sens Actuators B 97:182-189

Wardak C (2011) A highly selective lead-selective electrode with solid contact based on ionic liquid. J Hazard Mater 186:1131-1135

Wilson D, De los Arada MA, Alegret s, Valle del M (2010) Lead (II) ion selective electrodes with PVC membranes based on two bisthioureas as ionophores: 1,3-bis( $\mathrm{N}^{\prime}$-benzoylthioureido) benzene and 1,3-bis( $\mathrm{N}^{\prime}$-furoylthioureido) benzene. J Hazard Mater 181:140-146

Yin T, Pan D, Qin W (2012) A solid-contact $\mathrm{Pb}^{2+}$-selective polymeric membrane electrode with Nafion-doped poly (pyrrole) as ion-to-electron transducer. J Solid State Electrochem 16:499-504

Yuan XJ, Wang RY, Mao CB, Wu L, Chu CQ, Yao R, Gao ZY, Wu BL, Zhang HY (2012) New Pb(II)-selective membrane electrode 
based on a new Schiff base complex. Inorg Chem Commun 15:29-32

Zamani AA, Khorsihdi N, Mofidi Z, Yaftian MR (2011) Crown ethers bearing 18C6 unit; sensory molecules for fabricating PVC membrane lead ion-selective electrodes. J Chin Chem Soc $58: 673-680$
Zhang W, Jenny L, Spichiger UE (2000) A comparison of neutral $\mathrm{Mg}^{2+}$-selective ionophores in solvent polymeric membranes: complex stoichiometry and lipophilicity. Jpn Soc Anal Chem 16:11-18 